\title{
The Formation of the Genre System on Norwegian Broadcast Radio
}

\author{
Wenche Vagle
}

\begin{abstract}
This article deals with the formation and first development of the radio genre system in Norway in the interwar years (1925-1940). It is shown that the programmes of the 1920s were mostly imperfect reproductions of existent cultural forms. Yet, a beginning modernization of the genre repertoire took place in the 1930s. Whereas the rudimentary genre repertoire of the 1920s was built up through a plain copying from other domains in society, the latter half of the 1930s saw the introduction of a more advanced genre-generating process whereby new genres were formed through a mixing of two or more existing norms. This article also identifies a number of developmental trends that had their slow start in the 1920s and would mark the evolution of Norwegian radio's registers and genres ever since.
\end{abstract}

Keywords: early broadcasting history, radio programming in the interwar years, Norwegian radio genres and registers, developmental trends in radio's meaning patterns, text and genre history

\section{Introduction}

The topic of the present article is the establishment and initial development of the radio genre system in Norway. Historically, this phase in the evolution of the radio's genre system took place in the interwar years (1925-1940). With implicit or explicit reference to the radio's text history in the decades to follow, the article also identifies a number of developmental trends that had their slow start during these years.

The analysis has been guided by a number of analytical questions, such as: Which genres entered the radio medium, and when did they first appear? Which communicative goals and functions did they serve? Where did the genres come from - from which cultural domains within the Norwegian and international society? What did the textual structures of the genres "look like"? Did the transference of existing genres to the radio medium cause functional and/or structural changes? How much were the various genres exploited in the radio programming? If one looks at the radio's textual structures across the genre system as a whole, is it possible to detect developmental trends on the register level? When does the radio's genre structuration process go beyond the undeveloped norm transference stage and into the somewhat more advanced stage of genre mixture and synthesis?

Generally speaking, there are three kinds of data with concomitant methodical procedures that can be exploited for identifying, explicating and reconstructing the social norms, including genres, which underpin actual human practices: 
- One might attempt to gain access to the actors' norms and competences by consulting printed or written materials that are indexical of the social norms under scrutiny. This method is known as documentary analysis.

- One might look for the norms in the practices themselves. In cases in which the practices under scrutiny are discursive (i.e., communicative actions mediated through signs and texts), methodologies such as semiotic analysis, conversation analysis, text analysis, discourse analysis, frame analysis and genre analysis are at the researcher's disposition.

- One might seek to "bring out" practitioners' own understandings using interview or questionnaire techniques.

Of the three research schemes, I have applied a combination of the first two, i.e., documentary analysis (Syvertsen 1992) and discourse analysis (Fairclough 1995), primarily genre analysis (Bhatia 1993; Swales 2000; Berge 1990, 1993). Since the historical dimension - change, stability and evolution over time - is part of the research interest, the data have been sampled from different points in time, and the descriptive-inferential procedures have comprised techniques for detecting patterns of diachronic shift and permanence (see Dahl 2004).

The analysis has been based on information extracted from primary as well as secondary sources. When it comes to secondary sources, Dahl's historical account of Norwegian broadcasting (1999) has been an invaluable source. As for primary sources, the following have been used:

- The official (and near-contemporary) history of the old private Oslo broadcasting company (1925-1933) (Hougen 1932).

- NRK's official Annual Reports and Klæbo 1954.

- NRK's radio programme archive.

- A collection of personal memoirs and nostalgic popular publications (Kirkvaag 1953 \& 1980, Øksnevad 1946, Klæbo 1983, Hartberg 1986 and Jønsson [ed.] 1993).

- Hallo! Hallo! - a printed weekly programme magazine by Oslo Kringkastingselskap, which was taken over by the NRK after nationalisation in 1933.

To a large extent, the methodical procedures grew from the properties of the sources. The examination of the primary sources was carried out in chronological order beginning with the oldest material. The (re)reading of the secondary source material was steered by the temporal progression of the primary sources so as to allow me to use the various sources as checks and supplements to the others. The perused documentary sources are very explicit on matters of programming. The chronologically ordered examination of the primary source material allowed me to follow the unfolding of the genre system step by step.

\section{Previous Research}

Historical studies of the radio's programming, genres and textual practices are relatively few and far between in the Norwegian and international research literature. Nonetheless, aspects of the history of the radio's genres and linguistic registers - whether on 
Nordic, European or American ground - shine through in a number of publications on the radio medium (for example Nørgaard et al. 1975-1978; Åberg 1999; Poulsen 2006; Scannell 1996; Minkov 1980; Crisell 1986; and Hilliard 1985). The register level, i.e., the patterned linguistic (and paralinguistic) choices realising the radio's range of speech genres, seems to have received more attention than the genre level. Jonsson has formulated a general hypothesis about the evolution of radio language, assuming that the use of language has moved away from stylistic traits associated with formal, ceremonial and literate contexts towards features characteristic of informal, everyday-like and oral situations (1991: 193). Nordberg has attempted to characterise register changes pertaining to the marking of authority relations (which she refers to as the relationship between medium and audience). Her observations for Swedish broadcasting are very similar to those made by Scannell for British broadcasting. Nordberg sees the trend as going from distantiated and authoritarian patterns towards relaxed, informal and interactive communicative styles (Nordberg 1998: 162). ${ }^{1}$

When trying to generalise about the stylistic shifts that seem to have affected the linguistic practices of Norwegian and Swedish radio, Dahl and Nordberg have proposed generalised descriptions that capture similar tendencies summarised by Fairclough under the heading of conversationalisation (conversation, it will be recalled, is the prototypically spoken genre) (Fairclough 1995). Dahl and Nordberg perceive of the text norm changes in terms of a gradual progression from written towards oral modes of expression (Dahl 1999 [1975], Dahl 1999 [1978], Dahl \& Bastiansen 1999; Nordberg 1991, 1998).

When it comes to the genre level, both Norwegian radio's original 1925 genre system and its subsequent evolution have in fact been cursorily described in Dahl's volumes about the history of Norwegian broadcasting from 1923 till 1981. When put together, the chapters on programmes, programme forms and programming policy yield an outline of the evolution of the medium's genres and registers (Dahl 1975/99, 1978/99 and Dahl \& Bastiansen 1999).

\section{The History of Norwegian Radio Broadcasting in Table Format}

Since periodisations can be useful as initial orientations, allow me to present my periodisation of the history of Norwegian radio broadcasting juxtaposed with a widely accepted periodisation of Norwegian $20^{\text {th }}$ century history taken from a much used textbook on the subject - Berge Furre's Norsk historie 1905-1990 (1996). It is no doubt more than a coincidence that the periods of the two different periodisation schemes match each other almost perfectly.

"The broadcasting question" proved difficult to settle in the Norwegian context. Because of a lack of public means, a solution that placed the initiative and ownership in the hands of private interests was instituted in 1925. This settlement led to the formation of a system of four private, regional broadcasting monopolies situated in Oslo, Bergen, Ålesund and Tromsø, whose services were officially opened between 1925 and 1927. Among the companies, the oldest - the Oslo company Kringkastingselskapet A/S - held a dominant position in Norwegian broadcasting until nationalisation in 1933, when the four companies were cashed in by the State and fused to form Norsk Rikskringkasting (NRK) (Dahl 1999: 68). 
Table 1. The History of Norwegian Radio Broadcasting Correlated with the Country's General History

\begin{tabular}{|c|c|c|c|}
\hline \multicolumn{2}{|c|}{$\begin{array}{l}\text { The History of Norwegian } \\
\text { radio broadcasting }{ }^{2}\end{array}$} & \multicolumn{2}{|c|}{ The general history of Norway in the 20th century } \\
\hline & & \multicolumn{2}{|c|}{ "The new working day" \& World War I (1900-1920) } \\
\hline \multicolumn{2}{|c|}{ VERY OLD RADIO (1925-33) } & \multicolumn{2}{|c|}{$\begin{array}{l}\text { The interwar period I: Social crisis and splitting forces } \\
(1920-1935)\end{array}$} \\
\hline \multirow[t]{5}{*}{ OLD RADIO } & PHASE 1 (1933-40) & $\begin{array}{l}\text { The interwar period II: Towards a } \\
\text { new social order - the dawn of the } \\
\text { welfare society (1935-1940) }\end{array}$ & \multirow[t]{5}{*}{$\begin{array}{l}\text { The social-demo- } \\
\text { cratic order } \\
(1933-1973)\end{array}$} \\
\hline & War "parenthesis" & The German occupation (1940-1945) & \\
\hline & PHASE 2 (1945-1950) & The restoration (1945-1952) & \\
\hline & PHASE 3 (1950-1960) & $\begin{array}{l}\text { The social-democratic order } \\
\text { I: Growth \& hope (1952-1961) }\end{array}$ & \\
\hline & PHASE 4 (1960-1968) & $\begin{array}{l}\text { The social-democratic order } \\
\text { II: Growth \& protest (1961-1973) }\end{array}$ & \\
\hline \multicolumn{2}{|c|}{ NEO-OLD RADIO (1968-1982) } & \multicolumn{2}{|c|}{ The oil age and the crisis years (1973-1981) } \\
\hline \multicolumn{2}{|c|}{ TRANSITION (1982-1993) } & \multicolumn{2}{|l|}{ Back to the market (1982-1993) } \\
\hline \multicolumn{2}{|c|}{ NEW RADIO (1993 onwards) } & \multicolumn{2}{|c|}{ Post-industrial society (?) (1993 onwards) } \\
\hline
\end{tabular}

In the 1933 Broadcasting Act, the state-owned corporation was established as a nationwide broadcasting monopoly. Although the NRK was controlled by the state in matters concerning organisation and finance, it was fairly independent in its programming (Dahl 1999, Syvertsen 1992). The latter half of the 1930s saw large extensions in the medium's audience. Radio broadcasting became a mass medium with networks in all parts of the country, and the radio receiver became an ordinary household commodity, spreading "downward" in society to the lower social classes.

\section{The Establishment of Radio Genres}

\section{The Emergence of the Radio's First Genre System}

At the outset, Very Old Radio (VOR) was music radio with a share of musical content close to 60 per cent - spread over various types of music. The dominant verbal format was the straight talk. ${ }^{3,4}$ Other typical verbal genres were news telegrams, weather reports/forecasts, and commercial advertisements. Programme announcements, as well as time signals, also belonged to the radio's repertoire of sounds from the beginning. Along with The Children's Hour ${ }^{5}$ on Saturdays and church services on Sundays, these genres formed the original programme skeleton (Hougen 1932: 22; Dahl 1999: 63ff, 387).

Over the course of 1925 and 1926, the inventory of the radio's genre system grew to comprise a number of new elements: recitations, adult education, drama, cabarets, evening prayers from the studio, and various kinds of announcements. The opening years also saw the first "microphone reportages". Topping the list of public events selected for transmission were concerts, talks and dramatic performances - together 
with sports events (Hougen 1932: 60f, 93). In the early 1930s, a few live transmissions were even arranged to or from places abroad (Hougen 1932: 74ff). Despite the many production-technical weaknesses that hampered the production of outdoor broadcasts, the genre immediately started to expand (Hougen 1932: 61f) (see statistics in the appendix). In fact, the 1930s were the heyday of the live, full-length reportage on Norwegian radio.

The reportage is a "cover genre" consisting of text passages structured according to norms that constitute different genres in their own right. To begin with, radio sports reportages were practically monopolised by reports and running commentaries, whereas outdoor transmissions from public events like jubilee celebrations and official openings would also contain formal speeches and addresses. The interview, which later became a favourite reportage format, was taken into sporadic use in the late 1920s (Hougen 1932: 22ff; Dahl 1999: 73ff, 277). Although the reportage is a genre of information, it was quickly brought into use in the service of enlightenment and entertainment.

In 1927, three sister genres to talk were added to the repertoire: the causerie, ${ }^{6}$ the (Norw.) "kronikk" and the academic lecture. This was also the year when the gramophone cabaret, a genuine radio genre that was to keep growing on the schedule, became a normal part of programming. Incidentally, gramophone music was also increasingly exploited for filling pauses. Morning prayers and school broadcasts were taken on in 1931. Radio gymnastics, another international programme concept, came to Norway in 1930 but did not become a standard component of morning programming until after World War II (Dahl 1999: 320). Retransmissions of programming from international stations also appeared at regular intervals (Hougen 1932: 66f; Dahl 1999: 136).

Although they were not particularly frequent in the 1920s, soirees deserve special mention in a genre-developmental perspective. From 1928 onwards, a number of so-called "county soirees" featuring talks, causeries, recitations and musical performances were produced for the national network - as part of the ambition to integrate the nation culturally (Hougen 1932: 73ff). Together with the Children's Hours, the gramophone cabarets, a few Saturday evening cabaret programmes, and a handful of school broadcasting productions in the early 1930s, the soirees represent the first instances of mixed or composite programme formats within Norwegian broadcasting (Dahl 1999: 86).

Another emergent genre that merits special mention is the pedagogical dialogue, which was used experimentally in school broadcasting from 1931 onwards with the expressed intention of providing variation and relief from the monotonous genre that still prevailed - in school broadcasts, just as in other verbal broadcasts - the straight talk (Hougen 1932: 29ff).

\section{A Characterisation of the Radio's Genre System in the Early 1930s}

The programmes of the 1920s were mostly imperfect reproductions of existent cultural forms (predominantly "highbrow" ones). To a certain extent, The Children's Hour and the gramophone cabaret were honourable exceptions to this rule. ${ }^{8}$ In the case of the gramophone cabaret, it was only the global structure of organisation that was adopted (from the domain of public entertainment). Its "content" - the playing of records - was a creation of the new medium. In the case of The Children's Hour, the basic idea was 
fetched from the institutions of the family and the school (Hougen 1932: 34). But on its transference to the new medium, the format instantly proved to have a radiophonic quality that sets it apart from the other programmes of the VOR era.

If these few "genuine" radio genres are kept out of the picture, the inventory of the radio's genre system at the end of the VOR era looked something like the list below (sorted according to the source spheres of the different genres):

1. Traditional genres from the public sphere: concerts and other kinds of musical performances, dramatic pieces, cabarets, sketches, operas, talks, causeries, academic lectures, church services, formal speeches, programme announcements, gymnastics instruction, dialogues

2. Genres from modern media (other than the radio): commercials, news telegrams, weather reports/forecasts, various other kinds of announcements (stock exchange quotations, foreign exchange quotations, fishery reports, price information of rural products), reportages (reports, commentaries and interviews), "kronikk-s", linguaphone-like language teaching

3. Genres from the intimate sphere: prayers, songs, recitation (of short stories, fairytales, fables, novels, poetry), soirees

A nutshell characterisation of the radio programming in the VOR era could read as follows: The daily programme was incoherent, consisting of lengthy individual broadcasts with shorter or longer pauses between them. The individual broadcasts, on their part, displayed a strong internal coherence since they generally featured homogeneous texts structured according to one, and only one, generic norm. The different genres had kept their original form - or rather: the form they had at the time of their adoption by the new medium. Among verbal formats, the monologue ruled supreme. Although the inventory of the system had immediately started to grow, the genre repertoire was still relatively small and uniform. With respect to the four communicative obligations stipulated in the Broadcasting Charter, the major part of the programming was devoted to the goal of popular enlightenment. Education was also strongly supported. Yet, the goals of information and entertainment were also addressed.

\section{Developmental Trends Beginning in the VOR Era}

As we have seen, the radio programming underwent changes already during the VOR era. Indeed, what surfaced with the early changes was a number of developmental trends which have come to mark the evolution of the radio programming ever since. The trends go in the directions of:

- Greater diversity and variation in forms and contents

- Enhanced continuity

- Shorter texts

- Serialisation

- Fixed scheduling 
- Multi-voice formats

- Greater mixing of elements within programmes

- Growing accent on the communicative goals of information/actuality and entertainment (as well as opinion)

To complete the picture, one could also mention a couple of trends that did not emerge as developmental patterns until after the nationalisation of 1933, but rather took their starting points in the state of affairs that existed in the VOR era. These patterns of change are:

- The gradual shift from a narrow focus on culturally highbrow bourgeois topics towards a broader and more popular selection of topics, and

- The change in linguistic norm from the exclusive use of the traditional Dano-Norwegian standard ("Riksmål") towards a more inclusive language policy allowing different varieties of the two written standards of Norwegian, as well as dialects and sociolects.

Regarding the development towards greater diversity and variation in the choice of content and genre, it set in from Day One. So did the strive for heightened continuity. As for the shortening trend, it was not very conspicuous in the VOR period. Still, the normal length of the radio talk or lecture was set to 30 minutes instead of 45 , which was standard in other contexts (Dahl 1999: 83). Regarding serialisation, the first serialised dramatic production aired in 1926 (Dahl 1999]: 88).

The fixed programme schedule arrived late in Norwegian broadcasting - in fact, not before 1968 (Dahl \& Bastiansen 1999: 390). But the tendency towards fixed scheduling existed from the very beginning, with the issuing at regular hours of time signals, announcements, and weathercasts in connection with newscasts (Hougen 1932: 78, Dahl 1999: 94). The cyclic character of the programming was further enhanced with the gradual establishment of a week-periodic service of thematic talks and "kronikk-s" (Dahl 1999: 63, 91, 259, 387).

Another developmental tendency which lay in embryo as the VOR era phased out was the pattern of change from monologue towards multiparty formats. The journalistic interview and the philosophical/pedagogical dialogue were early exponents of this trend. Their breakthrough came in the mid-1930s - at which time other interactive formats started to emerge as well.

When it comes to the trend towards a greater mixing of programme elements, it is not manifest before well into the 1930s. But as an ideal and in the form of precursors, the concept of "mixed or composite programmes" was already there in the VOR era. As we have seen, the only items in the programming that deserved the characterisation "mixed" were the occasional evening soirees and cabarets, the gramophone cabarets, and the weekly Children's Hour on Saturdays (Dahl 1999: 86). Still, the programme makers strived to make the broadcasts more mixed, which shines through in their reporting on the programme production (Hougen 1932: 29ff).

Of the four overarching purposes broadcasting was expected to address, enlightenment remained the primary one in both the 1920s and 1930s (and continued to hold this position throughout the 1940s and 1950s). Education also held a strong position. Still, the germ of the growth in the other two declared goals - information/actuality and enter- 
tainment - can in fact be found already in the VOR era. As for information/actuality, it was first and foremost in the rise of the reportage that its first expansion was manifested.

Entertainment was and remained the least significant of the four communicative goals of Norwegian radio broadcasting until, say, the beginning of the 1980s. In the very first years, entertainment was addressed in pure form only in The Children's Hour and in the transmission of a certain amount of light music, including jazz and dance music. Nonetheless, the feeble start of what was later to become a never-ending (?) evolutionary progression towards more and more entertainment can probably also be traced back to the VOR era. Most notably, the share of light music went up with the intensified use of the record player that followed from the introduction of the electric pick-up in 1927. So did the amount of live sportscasts - as part of the general expansion of outdoor broadcasts.

Seen and Heard was the name of the daily evening causerie programme that was initiated in December 1927 (and that stayed on the programme menu for decades). The communicative ambitions behind this genre newcomer were related partly to entertainment, partly to information/actuality - as can be seen in the argumentation originally used when the programme concept was suggested by the Programme Council:

One ought to introduce a short, daily evening causerie programme, Sett og hørt, which should have the ambition of treating - through lively and thought-provoking accounts and reflections held in a spiritual form - partly events of the day and issues of current interest, and partly other questions and thoughts that deserve, or can be expected, to be of interest and significance for people of our times.

Furthermore, it was pointed out that the causerie should be:

$\ldots$ in a form and with a content that can be expected to have a reviving, cheering and entertaining effect on the majority of listeners.

Against the background of a programming policy that was calibrated to avoid raising controversy in society and that explicitly proscribed opinion and party politics from the programme menu, it is interesting to note that the causerie - together with the "kronikk" - stealthily came to introduce the expression, discussion and formation of public opinion to the spectrum of communicative goals in Norwegian broadcasting (Hougen 1932: 58f, Dahl 1999: 103f, 274f).

\section{Statistical Developments in Programming Across the 1930s}

The new broadcasting order inaugurated by nationalisation in 1933 did not cause any radical changes in the programming overnight. Most aspects of the programming remained basically as before. But the latter half of the 1930s did in fact bring symptoms of a beginning modernisation of the programming output. When sorted into "increasing categories", "decreasing categories" and "new categories", a comparison of the programme statistics of 1933-1934 to those of 1938-1939 provides a first view of the development. 
Table 2. Statistical Developments in Programming across the 1930 s (given in percentages)

\section{Increasing categories}

Gramophone music

Music in all

News \& weather

Actuality broadcasts

Drama (theatre performances, radio plays, sketches, etc.)

\section{Decreasing categories}

Church services \& prayers

Recitation

Talks

Language teaching

School broadcasts

Children \& youth

Miscellaneous (notably announcements)

New categories

Entertainment programmes

Discussions \& debates
$1931 \quad 1933-1934 \quad 1938-1939$

12.6

42.1

7.1

$\begin{array}{lll}7.1 / 10.0 & 6.7 & 8.1\end{array}$

$\begin{array}{lll}1.6 & 1.3 & 1.8\end{array}$

9.5

7.9

5.1

3.4

12.4

\} 14.8

2.9

3.8

17.5

48.0

11.3

2.2

1.8

9.5

2.6

2.0

1.5

6.3

10.4

1.6

8.1

$\begin{array}{lll}- & - & 3.0\end{array}$

\section{The Radio's Genre Growth in the 1930s}

The first years under the NRK saw the introduction of a handful of new genres or programme formats, which fall into two groups: (1) multi-party formats and (2) the first truly radiophonic genres. The new multi-party formats of the 1930s were: the classroom lesson, the conversation (an enlightenment genre), the discussion and the debate. The radiophonic genre newcomers were: the composite programme, the "microphone rolling" format, the sound picture, and possibly also the magazine format, which seems to have had its feeble start on Norwegian radio in the late autumn of 1939.

The composite programme and the classroom lesson developed within school broadcasting. Norwegian school broadcasting followed the course set by other European broadcasting companies, to the effect that proper talks were losing ground to "composite programmes with dialogues, classroom lessons - or at least children - in front of the microphone for questions and answers, and also microphone visits on location"( NRK's Annual Report 1933-1934, page 40). The multi-party opinion and enlightenment genres were first adopted by the Talks Department as alternatives to the straight talk. The sound picture was actually first used by the News and Actuality Department, but within a couple of years it had spread to the School Broadcasting Department, where it came to play a central role for decades to come.

The latter half of the 1930s represents a transitional phase in the medium's text history. About half of the new genres were the result of plain genre transference or of copying from other domains in society - in the same way that the medium had built up its rudimentary genre repertoire in the 1920s. This goes for the multi-party genres. The 
rest of the new genres, however, marked the introduction of a more advanced genregenerating process whereby new genres were formed through the mixing of two or more existing norms. Along with The Children's Hour from the VOR era, the remaining genre newcomers in the 1930s - the composite programme, the sound picture, and the magazine - were the first radio formats to be formed through such hybridisation processes. In many ways, these are the first radio genres that deserve the label radiophonic. Their formation presupposed the coming of recording technologies enabling rudimentary editing and montage techniques (see further Vagle 2007: 335f).

As before nationalisation, the radio's daily output consisted of a sequence of individual title or genre programmes - with shorter or longer pauses between them. This aesthetic based on title programmes remained the central principle of the radio's global text organisation until, say, the mid-1960s. Within the frames of this aesthetic, however, the systematic patterns of change that had emerged during the VOR era had their definite breakthrough, thereby initiating an evolutionary course that with time was to lead to fundamentally different ways of organising the global text structure - block formatting in the 1970s and1980s, and eventually flow formatting in the 1990s.

Let us look more closely at the part of this process which belongs to the late 1930s. A most conspicuous aspect was that the length of the individual programmes was gradually reduced. This gave room for a larger number of titles within the frames of the daily transmission time, thereby opening up to greater variation and flexibility in the programming output (Dahl 1999: 257f). The shortening trend applied to talks and music programmes in particular. New programmes of short duration were introduced - notably a news commentary programme lasting ten minutes (NRK's Annual Report 1938-1939: 22).

The increased use of gramophone music was another factor in the development towards more varied programming and enhanced continuity. The share of gramophone music continued to grow throughout the 1930s. In fact, a major part of the general increase in transmission hours was filled with gramophone music. For obvious reasons, it was easier to achieve variation in the musical repertoire with the gramophone than with a standing radio orchestra. What is more, the playing of gramophone music was an excellent means for filling pauses of unpredictable length so as to improve the overall coherence of the programming output (Dahl 1999: 267). The new station jingle and pause signal that were taken into use in April 1939 contributed to the overall coherence, and also created a recognisable identity on part of the radio channel itself (NRK's Annual Report 1938-1939: 27). In 1937 the morning programme became coherent, which contributed to the beginning perception of the radio's output as a united whole.

In certain respects, the concern for enhanced flexibility, variation and continuity was at odds with the drive towards fixed scheduling and serialised content, which also became stronger as the decade progressed. In other respects, the developmental tendencies all pulled in the same direction - as factors in the generation of a recognisable, cyclic and - in time - seamless texture particular to the ether medium. Regarding serialisation, the "kronikk" service that had been built up in the 1920s continued along the same lines as before, whereas the lecture series kept expanding in terms of elaboration and audience reach throughout the 1930s (NRK's Annual Report 1933-1934: 40; Dahl 1999: 257f, 267, 283). The trend towards fixed scheduling took major leaps forward with the introduction of the first daily "timetable" in November 1937. Incidentally, this innovation was originally established as a means of managing the new demands on the 
technical programming production deriving from the synchronisation of wavelengths. I cite the timetable in extenso, since it yields a concrete picture of what the national channel looked like (or rather sounded like) in the years before the war:

Part 1 11:30-11:45 Weather (new); school broadcasts; prayers and foreign exchange quotations

Part 2 12:55-15:00 Time signal; weather at sea (new on the national channel); fishery report; news; price information on rural products; afternoon concert (new on the national channel); local announcements (weather etc.)

14:00 New weathercast for Eastern Norway and Southern Norway from the stations in the eastern part of the country and from Kristiansand

Part 3 16:30 till The evening programme

app. 23:00

16:30-16:45 Gramophone concert

16:45-17:00 Commercials

17:00-17:05 Gale warning (new)

17:00-18:45 Concert, talks, recitations, etc.

(Translated from NRK's Annual Report 1937-38: 12)

One should not overstate what was achieved in the way of more continuous programming in the 1930s. The pace remained slow, and the pauses between programmes were ample. It was the war that finally brought the American "continuity radio" to Europe but the new impulses, mediated through British and Swedish broadcasting, did not arrive in Norway until in the 1950s. Thus, it was only from this time onwards that the ideals of fewer pauses, a quicker pace, shorter programme segments, higher precision, and a more friendly listener address left their mark on the programming output in earnest (Dahl \& Bastiansen 1999: 211ff).

The beginning tendency towards greater diversity and continuity on the level of the daily programming output was accompanied by a similar tendency on the level of the individual programme - namely, the trend towards more mixing of elements within programmes. Again, improvements in production facilities and technologies were crucial to the development (see further Vagle 2007: 326ff). One aspect of the development was the practice of mixing speech with music and sound effects. Another aspect was the method of combining text segments with different generic structures, which had started in the VOR era with The Children's Hour and the sporadically produced soirees. As one would expect, the practice of mixing speech, music and sounds was most notable within drama productions, but it was also taken up by school broadcasting. In fact, one of the new production technologies of the mid-1930s - the archive of recorded sound effects - was only exploited in school broadcasts (in pedagogical dialogues and in sound pictures) to begin with. With the expansion of the reportage, a third area of programming was quickly being affected by the new radiophonic multimodality, namely news and actuality.

The foremost carrier of the mixing trend was a new genre that was constituted under the name the composite programme. From a present-day perspective, it can be ascertained that the formation of this genre was part of a major shift in the basic principle of the radio's aesthetics - the shift from genre to format. This larger process of change 
seems to have passed through four stages - with the characteristic programme forms in question being (1) the genre programme, (2) the composite or mixed programme, (3) the magazine, and (4) the flow format. The 1930s saw the emergence of the second stage, as well as the very first instances of the programme form that marked the third stage, namely the magazine.

The breakthrough of the composite programme came after the war, when the label montage programme was also taken into use. The composite programme, as it was called in the 1930s, was a genre of enlightenment and education (and still is - on the channel where it exists even today, NRK P2). As can be inferred from the name, composite programmes are constructed from material of various generic origins - causeries, poetry declamation, prose recitation, dramatised episodes, songs, music, commentaries, interviews, reportage clippings, discussion or conversation segments, ambient sounds, etc. The material is often pre-recorded. In the 1930s, programmes were composed of a relatively restricted number of these ingredients, and each segment was relatively long. In the decades following the war, the programme format grew increasingly more complex.

The radio magazine (or block format) also developed in the early 1930s - within the contexts of European public radio services, that is (Jauert \& Prehn 1995: 135). In a Norwegian context the magazine is really a post-war phenomenon. Still, programme secretary Thorstein Diesen seems to have been involved in the production of the first instances of Young Peoples' Radio Magazine during the autumn of 1939 (Dahl, personal communication). As is well known, the breakthrough of the magazine format on Norwegian radio did not come until the early 1960s, with the popular morning programme Reiseradioen/Nitimen, which was formed in response to the new listener habits of "distracted secondary-activity listening". The heyday of the format was also late in a Norwegian context, and did not take place until the 1970s and 1980s (Dahl \& Bastiansen 1999: 377ff).

Of course, decisive preconditions for these trends are to be found at the technical level in the form of improved production and transference technologies (e.g., an increasing number of production rooms, a more ample supply of long-distance telephone lines and other technologies for fetching programming from outside the station, the construction of the so-called "high-frequency channel", the coming of apparatuses for switching between different sound sources, and also of recording technologies and mobile production units) (see further Vagle 2007: 320ff).

However, what represented a major driving force for the described changes in the programming output were the new ideas about broadcasting-mindedness and ear-friendliness that arose in the mid-1930s. The first time this new awareness of presentational forms favourable to reception through the ear surfaced in the NRK's official documents was in 1934. In the Annual Report covering the budgetary year 1933-1934, the Chief of Programming notes that direct transmissions are still the most frequent, but - he says - "specially arranged programmes" are also being produced. Two years later, the medium-minded practice has evidently expanded. In the Annual Report covering the budgetary year 1935-1936, the development is described as follows:

Gradually, broadcasting has given up the practice of transmitting programmes that one is offered. It is becoming more and more common that the NRK itself takes the initiative and carries out the preparation and production of the programmes. 
With this procedure, it is possible to make the programme as a whole more suited for listening, since one only has to take into account the broadcasting situation. Furthermore, one has broken the programmes down into shorter segments. As a result, the programmes are becoming less constrained, more varied and more many-sided, so that they to a certain extent can give a more complete picture of the country's cultural life. ${ }^{9}$

This novel broadcast-minded awareness quickly came to affect the programmes produced by the Talks Department and the Department of School Broadcasting as well as the Actuality and News Department.

This new self-consciousness on part of the young medium also extended to linguistic practices. It was as part of this idea that Chief of Programming Olav Midttun for the first time expressed the ambition that radio speakers should make an effort to use more oral forms of expression. Before the advent of recording and editing techniques, the elaborate, word-by-word manuscript was an indispensable tool for the production of radio speech, whether in monologue or dialogue format. Unfortunately, speech delivered from script is invariably accompanied by a flat tone colour and a certain lack of expressiveness. When practiced by untrained speakers quivering from nervousness in front of the microphone in a hot studio, the delivery tended to sound stiff and inauthentic (Nyre 2003: 152f). Despite the beginning effort to make radio speakers sound more natural, it would be several decades before this goal was realized.

The growth of the use of multi-voice formats obviously also contributed to the greater compositeness inside programmes. If the VOR era had seen a nascent pattern of change towards more use of multi-voice formats, the latter part of the 1930s saw its breakthrough. About half of the new radio genres that came into being between 1934 and 1939 were interactional ones (the genres in question being the classroom lesson, the enlightenment conversation, the discussion and the debate). As for the journalistic interview and the pedagogical dialogue, which had already emerged around 1930, they kept gaining ground throughout the 1930s. Still, monologue formats continued to dominate the verbal output until far into the 1960s.

The interview had arrived with the first introduction to radio of journalistic production practices around 1930, and as is well known this genre has kept growing in the medium ever since. The fate of the pedagogical dialogue was very different. Once introduced in the early 1930s, it quickly came to replace the talk or lecture as the most frequently exploited programme form in school broadcasting, where it remained a rising star throughout the 1930 s, only to fall flat to Earth sometime during the war.

The chance of the new multi-voice formats was mixed. The classroom lesson with its strained imitation of classroom activities (mostly teacher-class interrogation) - quickly proved to be an awkward form, and was taken out of use again (NRK's Annual Report 1936-1937: 18). When it comes to the discussion and the debate, these eventually became staple forms of talk in Norwegian broadcasting, but it took close to two decades for them to reach significant levels of exploitation (Dahl \& Bastiansen: 1999: 214, 268).

In characterisations of Norwegian broadcasting before the 1980 s, the story normally told about the monopoly periods ${ }^{10}$ is that the old programming policy with its traditional communicative goals stayed intact, more or less unaltered, the whole period. 
Yet, radical changes did in fact affect the relational dimension of the communicative situation during the $1930 \mathrm{~s}$ - simply because the identities of the communicating parties were transformed with nationalisation and the geographical and social spread of the new medium. In the VOR era, radio had belonged to the restricted social group of the urban bourgeoisie. The new state authority disturbed the symmetry between the production and reception sides that had formerly ruled. The inclusion of new social groups in the broadcasting experience, which resulted from the expansion of networks in all parts of the country and the lowered costs of receiver apparatuses, did away with the old order. The enlightenment project from the VOR era continued, but was carried out from a different perspective and with new attitudes vis-à-vis the beneficiary party. In fact, two new - and partly contradictory - stances to the audience appeared. The most well known is probably the paternalistic "schoolmaster" tone with which the state institution addressed its audience. But the period also saw the onset of a more democratic definition of the relationship, by which popular education was required to be provided, not only for the people, but actually also by the people. The most exploited generic means for achieving this new goal was the reportage interview. Since one of the declared objectives of the new institution was to be a forum of the national public sphere, the enlightenment project was gradually adjusted so as to comprise "political enlightenment" - hence, the emergence of opinion genres such as the debate and the discussion.

That the pace of change was slow is a truth in need of some modification. When it comes to the category of "Actuality", it had in fact experienced a steep climb already during the VOR era and this climb continued throughout the 1930s. At this stage, certain qualitative developments also appeared. The old practice of merely reproducing NTB news telegrams was replaced by more independent methods of news gathering and editing. Furthermore, radio news stories acquired a structure that was different to that used by the press: stories were shortened and had more immediate news value. As a means of keeping listeners informed about the unfolding of processes that had been treated in former newscasts, one started to select topics and events for coverage more carefully so as to gain greater topical concentration and enhanced continuity from one newscast to the next (Dahl 1999: 271ff).

The reportage production also underwent significant changes in the latter half of the 1930 s. The old practice of merely accepting "what was on offer" in society was gradually abandoned. Reportages were increasingly planned and created at the initiative of the NRK's editorial leadership. Rather than simply distributing material that had been created for the purpose of non-broadcast situations, the NRK began to maintain its editorial right to select topics and events for radio programming independently of the interests and desires of the various providers of material. The coverage of foreign affairs also widened (Dahl 1999: 270ff).

Technical improvements evidently had a decisive impact on these discursive changes. In the case of reportage production, the most influential modernisations were the improvement of transference lines and the advent of sound-preservation media and mobile production equipment in the mid-1930s.

Entertainment was, and remained, the least significant of the four overarching communicative goals - in the 1930s and for decades to come. In terms of the share of the total number of broadcast hours, the percentage of entertainment programmes was a 
mere 2.5 in $1935-1936$ - rising to 3.0 in 1938-1939. To begin with, the entertainment programmes of the 1930 s seem to have been produced in the tradition of the soirees from the 1920s - judging from a description by Chief of Programming Olav Midttun:

These programmes can last up to 2-3 hours. They are as varied as possible, with an orchestra ensemble, songs, ballads, recitation, sketches etc. by actors, cabaret artists and others (NRK's Annual Report 1935-1936: 29).

As the decade progresses, inventive genres like "radio ball" and "film clip programme" are mentioned with increasing frequency in the reports - together with traditional light music genres such as musicals and variety shows.

As the 1930s ebbed out and the history of the "new" medium approached a quarter of a century, the gradual shift in the weighting of its four privileged communicative goals, which was to mark its programming ever after, had become unmistakably manifest. Entertainment had come to stay, even if its breakthrough was still decades away (it would not come until the 1950s with the studio shows). When measured in terms of shares of the annual output, the amount of programming addressing the communicative goal of information had exceeded that of enlightenment.

Gradually, the various developmental trends identified in the analysis radically changed the character of radio output, but this is a story that belongs to later periods in the medium's history. It was not until the 1960s that the growth of news and actuality programming reached exponential heights. As for entertainment, it took yet another decade or two before such a rate of acceleration was reached - with the proliferation of new infotainment hybrids taking off in the 1980s.

\section{Concluding and Widening the Historical Perspective}

What the analysis above has uncovered can be interpreted as a continuous process of genre differentiation reflecting the growing complexity of Norwegian society in the 1920 s and 1930s. When it comes to the generic innovation represented by opinion genres, it is particularly easy to identify the relevant agents of change on the societal level, namely nationalisation and the new role the medium was expected to play as a forum for the national public sphere.

This is how Dahl characterises Norwegian radio programming in the 1930s: it remained reproductive, even conservative, throughout the decade (1999 [1975]: 284). As the present study has shown, however, a beginning modernisation of the genre repertoire nevertheless took place during the 1930s. Radio programming was in fact qualitatively changed when the 1930s phased out as compared to what it had been when the decade began. The patterns of change that had emerged during the VOR era had gradually become more noticeable as the decade progressed. Even more interestingly, part of the modest growth that the genre system went through during these years had come about by way of a different kind of genre-generation process than before, namely hybridisation or the mixing of two or more existing genres. Thus, what we see in this shaping - I would claim - is the coming of a new, and different, phase in the medium's text history.

If one extends the historical perspective so as to look at the formation of the genre system of Norwegian radio as a whole, three different phases stand out relatively clearly. What appears is a genre structuration process that starts with norm transference and a 
characteristic discontinuous, title-programme-centred aesthetic, only to progress through the genre mixing \& synthesis phase with the gradual spreading of the block/magazine format, and then finally reaches the norm innovation phase with the advent of the flow format. Of course, there is a certain amount of overlap between the three phases, as there will always be when new cultural forms replace old ones. The table below displays the structuration process in some detail:

Table 3. Structuration of the Genre System of Norwegian Radio

\begin{tabular}{lll} 
Phases & $\begin{array}{l}\text { Dominating mode of } \\
\text { norm structuration }\end{array}$ & Description \\
\hline $\begin{array}{l}\text { Phase 1: } \\
\text { 1925-1940 }\end{array}$ & Genre transference & $\begin{array}{l}\text { An essentially title-programme-centred aesthetic, } \\
\text { although with infrequent and sporadic block-like pro- } \\
\text { grammes and with a beginning tendency towards fixed } \\
\text { daily/weekly scheduling. }\end{array}$ \\
\hline
\end{tabular}

Phase 2: Genre mixing Just before the war: Emergence of new radiophonic 1945-1987 and synthesis formats facilitated by improved production and transference technologies, notably the "composite programme" and the magazine.

1945-1950: The global organisation of the schedule remains basically as before the war, but the trend towards shorter programmes continues and the total number of programmes increases. The block or magazine format slowly starts to gain ground - especially in programmes directed at children and adolescents.

1950-1960: The magazine format continues to expand. The golden age of the family show, a mixed format. 1960-1968: Definite breakthrough of the magazine/block format, but the schedule continues to be dominated by genre programmes.

1968-1981: The ratio of magazines and traditional genre programmes is about 1:1.

1982-1987: The heyday of the block format, which dominates in both the public-service sector and the nonprofit, local-radio sector (where it fits in with the system of frequency sharing). The coverage of cultural topics, which used to be the bastion of title programmes, is now deferred to the magazine format. Yet, title programmes continue to have a certain hold on NRK P1 (the "old" P1 channel).

Phase 3: Genre innovation 1987 onwards With the opening-up to commercial local radio in 1988
comes the flow format and the establishment of Amer-
ican-style formatted radio. The original programme-
centred aesthetic has become practically extinct. A
rough estimate of the ratio between flow and block
programming is $1: 1$. 


\section{Notes}

1. Readers interested in an overview of the wider area of "radio research" might consult a research survey by Åberg, Vagle \& Poulsen (1999). Readers looking for a systematisation of trends and traditions in Nordic broadcasting research might turn to Gramstad \& Syvertsen (1997).

2. The labels used in this column, as well as the fundamental Old/New distinction, are inspired by Hujanen \& Jauert (1998).

3. Talk in this context is used in its specialised sense as a genre label, corresponding to the Norwegian designation "foredrag".

4. All translations of genre labels from Norwegian are by the author, as are translations of citations from historical sources. The Norwegian originals can be found in my dissertation (Vagle 2007).

5. From the very beginning, the programme consisted of a mixture of generically different elements - songs, music, fairytales, animal fables, radio drama, etc. (Hougen 1932b: 33f).

6. The causerie is a light, entertaining version of the talk.

7. The Nordic genre known as the "kronikk" resembles the genre called news analysis in English-speaking societies.

8. Another exception can perhaps be made for the reportage, whereby new structural elements and informational functions immediately took form as a result of the brand new capabilities of the medium notably, the medium's ability to report "live" on occasion from an event in progress via authentic sound documentation and its efficient, practically intermission-free distribution of messages. It nevertheless took 20 years or so before these new capabilities were fully naturalised and exploited for what they were worth.

9. Many of the same ideas about the specificity of listening, broadcast-mindedness (or "radiomässighet") and the use of differentiated programme forms for reaching larger groups of the audience were discussed within Swedish broadcasting in the mid-1930s (Nordberg 1998:149ff).

10. Broadcasting in Norway prior to 1981 comprises both the early period of regional monopolies (19251933) and the NRK monopoly (1933-1982).

\section{Bibliography}

Bhatia, V.K. (1993) Analysing Genre: Language Use in Professional Settings. London \& New York: Longman.

Berge, K.L. (1990) Tekstnormers diakroni. Noen idéer til en sosiotekstologisk teori om tekstnormendring [The diachronicity of text norms. Some ideas on a sociotextological theory about text norm change]. MINS 33. Stockholm: Stockholm university

Dahl, H.F. (1999) Hallo - hallo! Kringkastingen i Norge 1920-1940 [Hello-Hello! Broadcasting in Norway 1920-1940]. Oslo: Cappelen.

Dahl, H.F. \& H. G. Bastiansen (1999) Over til Oslo. NRK som monopol 1945-81 [Over to Oslo. NRK as a monopoly 1945-1981]. Oslo: Cappelen.

Dahl, H.F. (2004) Mediehistorie: Historisk metode i mediefaget [Media history: history methodology in media studies]. Oslo: Damm.

Fairclough, N. (1995) Media Discourse. London: Edward Arnold.

Furre, B. (1996) Norsk historie 1905-1990 [Norwegian history 1905-1990]. Oslo: Det Norske Samlaget.

Hartberg, Ø. (1986) Onkel Lauritz [Uncle Lauritz]. Oslo: Gyldendal Norsk Forlag.

Hougen, J. (1932) Oslo kringkastingselskaps historie. Vol II: Programvirksomheten [The History of Oslo Broadcasting Company, Vol. II: The Programming]. Oslo: Olaf Norli.

Hujanen, T. \& Jauert, P. (1998) 'The New Competitive Environment of Radio Broadcasting in the Nordic Countries: A Short History of Deregulation and Analysis', Journal of Radio Studies 5 (1).

Jauert, P. \& Prehn, O. (1995) Lokalradio og lokal-tv. Nu og i fremtiden [Local radio and local television. Now and in the future]. København: Kulturministeriet.

Jonsson, Å. (1991) “"Snälla Radiotjänst!” Sex decenniers lyssnarbrev med språkliga synpunkter' [“"Dear Radio!" Six decades of letters to the editor from listeners concerning questions of language'], in: Brändström, A. \& Åkerman, S. (eds.): Icke skriftliga källor [Non-written Sources]. XXI Nordiska Historikermötet. Umeå: Umeå University.

Jønsson, B. (ed.) (1993) Svingende bølger [Swinging waves]. Oslo: Eidem Forlag.

Kirkvaag, R. (1953) Bak mikrofonen [Behind the microphone]. Oslo: Aschehoug.

Kirkvaag, R. (1980) Kom ncermere! [Come closer!]. Oslo: Gyldendal.

Klæbo, A. (1954) Dette er Norsk rikskringkasting [This is Norwegian national broadcasting]. Oslo: Norsk rikskringkasting/Fabritius \& sønners forlag.

Klæbo, A. (1983) Radioliv med NRK i 50 år [Radio life with NRK through 50 years]. Oslo: Gyldendal norsk forlag. 
Minkov, M. (1980) Radio Journalism. The International Organization of Journalists

Nordberg, K. (1991) 'Skriftligt och muntligt i radion' [ 'Orality and literacy in radio'], in Brändström, A. \& Åkerman, S. (eds.) Icke skriftliga källor [Non-written sources]. XXI Nordiska Historikermötet. Umeå: Umeå University.

Nordberg, K. (1998) Folkhemmets röst. Radion som folkbildare 1925-1950 [The Voice of the Folkhem: Radio as Adult Educator 1925-1950]. Stockholm/Stehag: Brutus Östlings Bokförlag Symposion.

Nørgaard F. et al. (1975-1978) De musiske udsendelser DR 1925-1975: Radioteater, musik, TVteater [Music Programmes in Denmark 1925-1973: Radio Drama, Music, Television, Theatre]. København: Nyt Nordisk Forlag.

Poulsen, I. (2006) Radiomontagen og dens rødder. Et studie i den danske radiomontage med vagt på dens genremcessige forudscetninger [The Radio Montage and Its Roots. A Study in the Danish Radio Montage With Emphasis on Its Preconditions of Genre]. Roskilde: Roskilde Universitetsforlag.

Scannell, P. (1996) Radio, Television \& Modern Life. Oxford: Blackwell.

Syvertsen, T. (1992) Public Television in Transition. A Comparative and Historical Analysis of the BBC and the NRK. Levende bilder 5 (1992). The Norwegian Research Council for Science and the Humanities (NAVF). Oslo \& Trondheim: NAVF and the author.

Swales, J.M. (2000) Genre analysis: English in academic and research settings. Cambridge applied linguistics series. Cambridge: Cambridge University Press.

Vagle, W. (2007) "I think the listeners would like me to ask you, Mr Prime Minister, ...". The history of texts and contexts in Norwegian radio with emphasis on the early period. Acta Humaniora 317. Doctoral dissertation, Faculty of Humanities. Oslo: University of Oslo.

Øksnevad, T. (1946) Det lå i luften [It was in the air]. Oslo: Aschehoug.

Åberg, C. (1999) Den omärkliga tekniken. Radio- och tv-produktion 1925-1985 [The Unnoticeable Technology. Radio and Television Production 1925-1985]. Stockholm: Natur \& Kultur

Wenche Vagle, Cand. Philol., Researcher, Department of Teacher Education and School

Research, University of Oslo, wenche.vagle@ils.uio.no 


\section{Appendix: Programme statistics, 1925 till 1938-1939"}

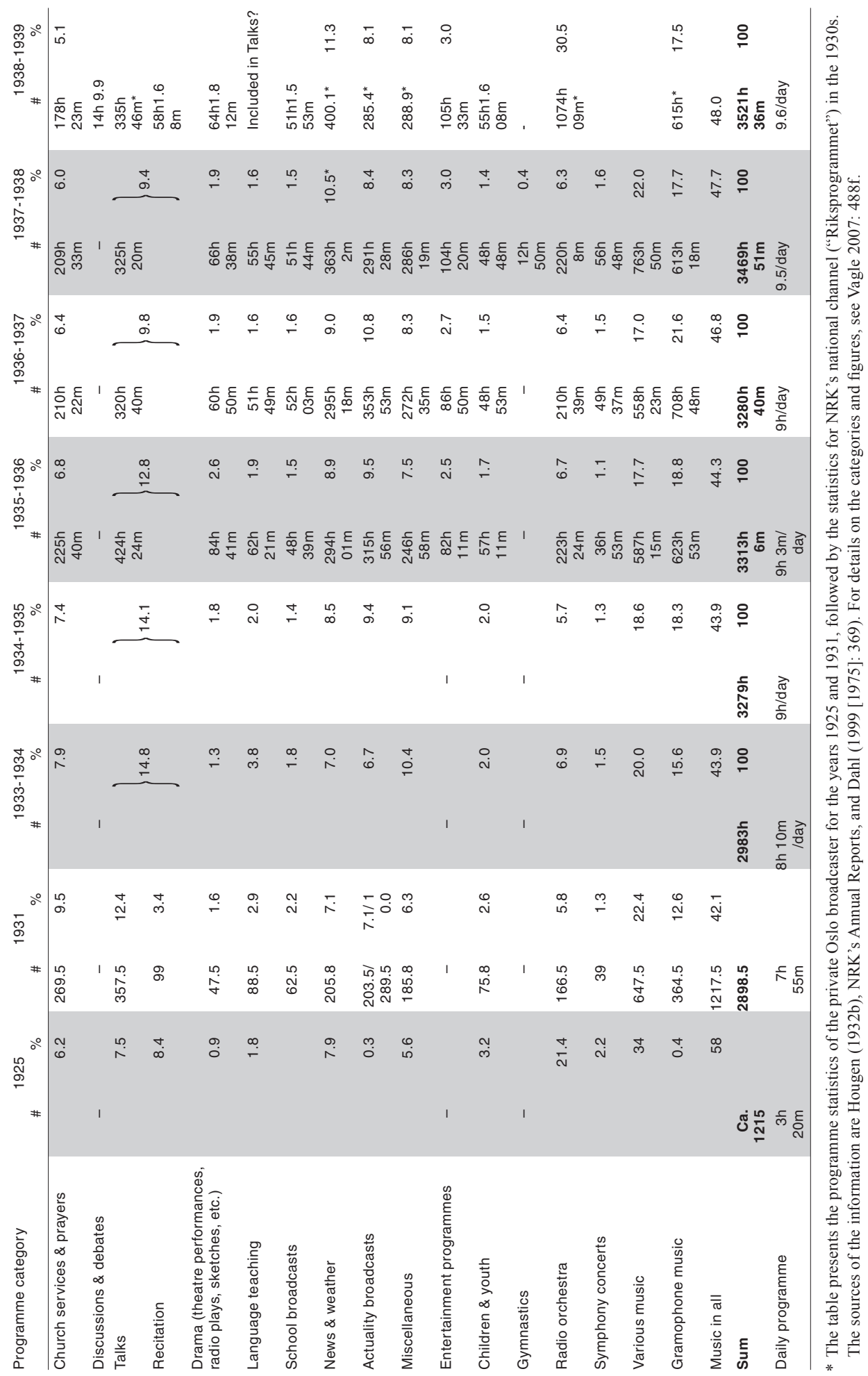

